\title{
Visual impairment and medication safety: a protocol for a scoping review
}

\author{
Sally J. Giles ${ }^{1,2^{*}} \mathbb{D}$, Maria Panagioti ${ }^{1,2}$, Lisa Riste ${ }^{1}$, Sudeh Cheraghi-Sohi ${ }^{1,2}$, Penny Lewis ${ }^{3}$, Isabel Adeyemi ${ }^{1}$, \\ Karen Davies ${ }^{1}$, Rebecca Morris ${ }^{1,2}$, Denham Phipps ${ }^{3}$, Christine Dickenson ${ }^{3}$, Darren Ashcroft ${ }^{1,3}$ and \\ Caroline Sanders ${ }^{1,2}$
}

\begin{abstract}
Background: The number of individuals with a visual impairment in the UK was estimated a few years ago to be around 1.8 million. People can be visually impaired from birth, childhood, early adulthood or later in life. Those with visual impairment are subject to health inequities and increased risk for patient safety incidents in comparison to the general population. They are also known to be at an increased risk of experiencing medication errors compared to those without visual impairment. In view of this, this review aims to understand the issues of medication safety for VI people.

Methods/design: Four electronic bibliographic databases will be searched: MEDLINE, Embase, Psyclnfo and CINAHL. Our search strategy will include search combinations of two key blocks of terms. Studies will not be excluded based on design. Included studies will be empirical studies. They will include studies that relate to both medication safety and visual impairment. Two reviewers (SG and LR) will screen all the titles and abstracts. SG, LR, RM, SCS and PL will perform study selection and data extraction using standard forms. Disagreements will be resolved through discussion or third party adjudication. Data to be collected will include study characteristics (year, objective, research method, setting, country), participant characteristics (number, age, gender, diagnoses), medication safety incident type and characteristics.
\end{abstract}

Discussion: The review will summarise the literature relating to medication safety and visual impairment.

Keywords: Medication safety, Visual impairment

\section{Background}

Visual impairment (VI) refers to a condition where the person has a reduction in their visual acuity or field of vision, which cannot be corrected by spectacles or contact lenses. It is estimated to affect 285 million people, 39 million of whom are blind [1]. The number of individuals with a visual impairment in the UK was estimated a few years ago to be around 1.93 million [2]: about $3 \%$ of the adult population [3]. People can be visually impaired from

\footnotetext{
*Correspondence: sally.giles@manchester.ac.uk

${ }^{1}$ NIHR Greater Manchester Patient Safety Translational Research Centre, University of Manchester, Suite 11, 7th floor, Williamson Building, Oxford Road M13 9PL, Manchester, UK

${ }^{2}$ Centre for Primary Care, University of Manchester, Oxford Road M13 9PL, Manchester, UK

Full list of author information is available at the end of the article
}

birth, childhood, early adulthood or later in life. People over 50 represent the largest group of blind and visually impaired people, which currently stands at $82 \%$ of the blind and visually impaired population worldwide [1]. Those with visual impairment or blindness are reported to be marginalised in terms of accessing healthcare information and facilities, and they are known to receive suboptimal healthcare [4]. Marginalised patients, such as those with visual impairment, are subject to health inequities and increased risk for patient safety incidents in comparison to the general population [5]. Studies also suggest that people with VI are more at risk of social isolation [6], which could further perpetuate their increased risk of being affected by patient safety incidents. Those with visual impairment are known to be at an increased risk of

(c) The Author(s). 2021 Open Access This article is licensed under a Creative Commons Attribution 4.0 International License, which permits use, sharing, adaptation, distribution and reproduction in any medium or format, as long as you give appropriate credit to the original author(s) and the source, provide a link to the Creative Commons licence, and indicate if changes were made. The images or other third party material in this article are included in the article's Creative Commons licence, unless indicated otherwise in a credit line to the material. If material is not included in the article's Creative Commons licence and your intended use is not permitted by statutory regulation or exceeds the permitted use, you will need to obtain permission directly from the copyright holder. To view a copy of this licence, visit http://creativecommons.org/licenses/by/4.0/ The Creative Commons Public Domain Dedication waiver (http://creativecommons.org/publicdomain/zero/1.0/) applies to the data made available in this article, unless otherwise stated in a credit line to the data. 
experiencing medication errors [7] compared to those without visual impairment. This could be for a number of reasons, such as being unable to open medication containers, being unable to differentiate various types of medication containers, being unable to differentiate various types of tablets/capsule dosage forms, forgetting to take medication on time and taking the wrong medication [7, 8]. Medicine-taking is complex and requires various and coordinated forms of work on the part of the patient and those in their networks. People with VI may not be able to perform their medicine work as easily as those without VI. The importance of supporting visually impaired patients to help improve their medication safety was further strengthened in 2016 when NHS England introduced the Accessible Information Standard (AIS), which required that the information and communication needs of disabled patients are proactively addressed in all aspects of NHS healthcare, including the dispensing of medicines [9]. Digital solutions are increasingly used to improve people's safety and quality of life and VI people are frequent users of the Internet to support their wellbeing $[10,11]$. There are concerns about the cost and lack of universal availability of this technology [12], and it is less clear how digital technologies, managed by individuals, can not only empower visually impaired people, but also safeguard them from harm related to medication management [13].

\section{Rationale}

To understand the issues of medication safety for VI people, it is essential to gather evidence from their experience and consider that alongside previous research. We have undertaken focus groups with VI people identifying a number of key themes, including the variation in VI and consequences for medication safety. We propose conducting a scoping review of existing research evidence to increase the understanding of VI and medication safety.

The issues of medication safety for people with VI depend on the nature/severity of the visual condition. Previous research conducted by the team [14] identified that health and social care practitioners lack knowledge and understanding of VI, but many people with VI feel confident to explain what works for them and find "work arounds" to maintain safety in medicine taking.

With an ageing population in many developing countries, the number of people with age-related vision loss is likely to increase. The scoping review aims to identify the specific medication safety issues for people with visual impairment and how these patients manage their medicines to mitigate against medication safety issues.

\section{Objective of the scoping review}

To identify and analyse the existing literature relating to the association between medication safety and visual impairment, including the main types of and contributory factors to medication safety issues.

\section{Methods}

Firstly, "to examine the extent, range and nature of research activity; this type of rapid review might not describe research findings in any detail but is a useful way of mapping fields of study where it is difficult to visualise the range of material that might be available." The second common reason is determining whether a systematic review is feasible and of value. The third and fourth common reasons seem to describe scoping reviews that are not exploratory or preparatory, but done in their own right. Other authors similarly state that scoping reviews are used to synthesise research evidence and are often used to map existing literature in a given field in terms of its nature, features and volume. As such, scoping reviews have also been called "mapping" reviews. Finally, a map of the range of the available evidence can be undertaken as a preliminary exercise prior to the conduct of a systematic review. If we wish to conduct other more systematic reviews, then this review will allow us to see where and if that might be possible.

\section{Search strategy}

Four electronic bibliographic databases will be searched: MEDLINE, Embase, PsycInfo and CINAHL. We will also identify eligible studies by checking the reference lists of those studies identified in the search that meet our inclusion criteria. Our search strategy will include search combinations of two key blocks of terms: visual impairment and medication safety (Table 1), similar to those used in two previous reviews $[15,16]$.

The proposed search terms are shown in Table 1.

\section{Eligibility criteria}

Studies will be excluded if they fail to meet any of the 3 criteria (a "NO" choice). Studies will be eligible for fulltext screening if they fully (a "YES" choice to each criterion) or partly (one or more "UNSURE" choice) meet criteria A1, A2 and A3.

A. For any study type (including review articles and opinion pieces):

1) Is it an empirical research? YES, NO, UNSURE

2) Does it make reference to medication safety or medicines management?

YES, NO, UNSURE 


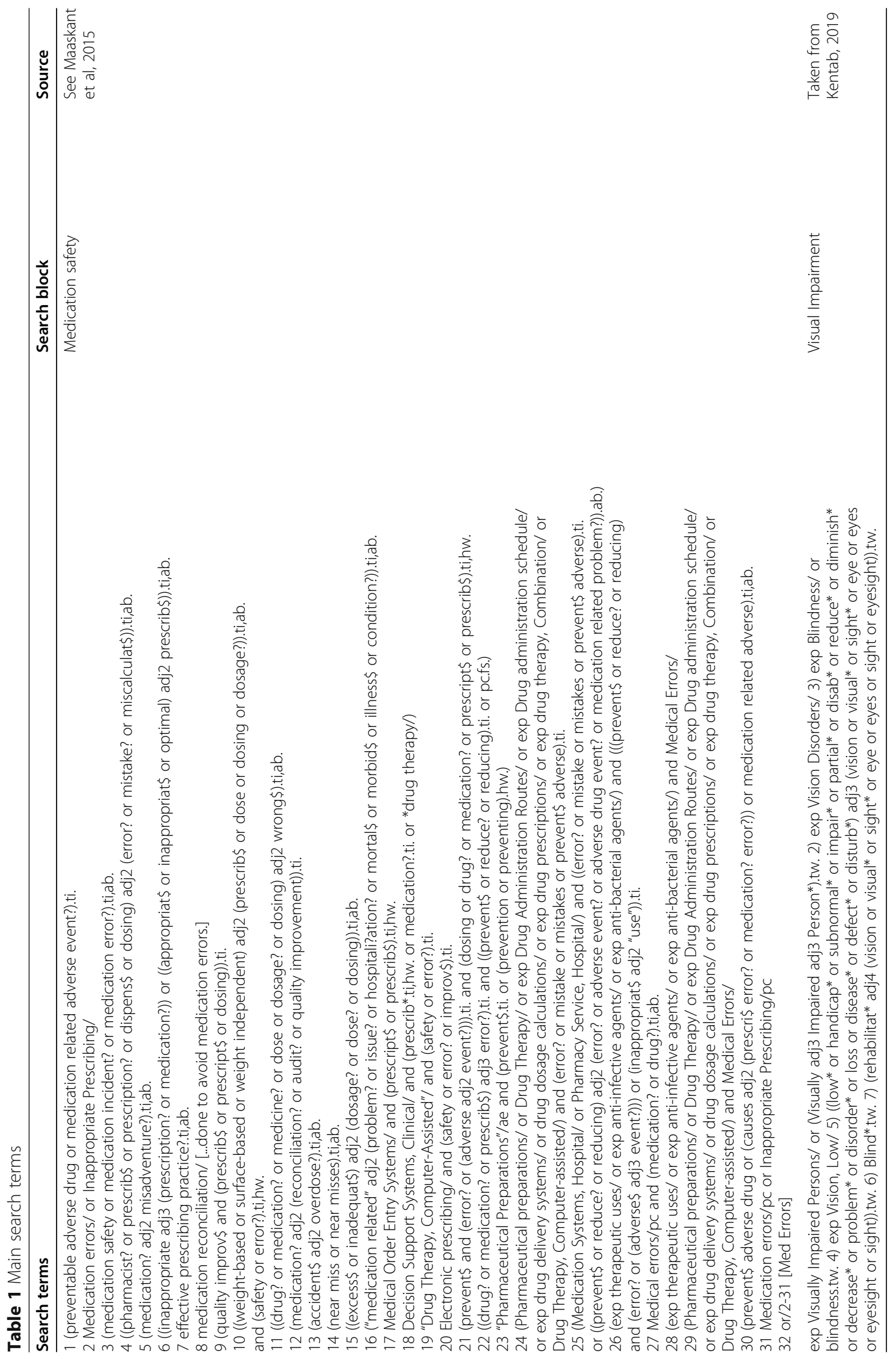


3) The research has been conducted with visually impaired patients?

YES, NO, UNSURE

We will include:

Types of studies: We will include empirical studies which provide data on medication safety or medicines management for visually impaired patients. Study designs will not be restricted and will include both quantitative designs (that is, randomised controlled trials, quasi-experimental studies, cohort studies, crosssectional studies) and qualitative studies including case studies. We will also include grey literature reports.

Types of participants: patients with visual impairment. We will not exclude participants on the basis of comorbidities

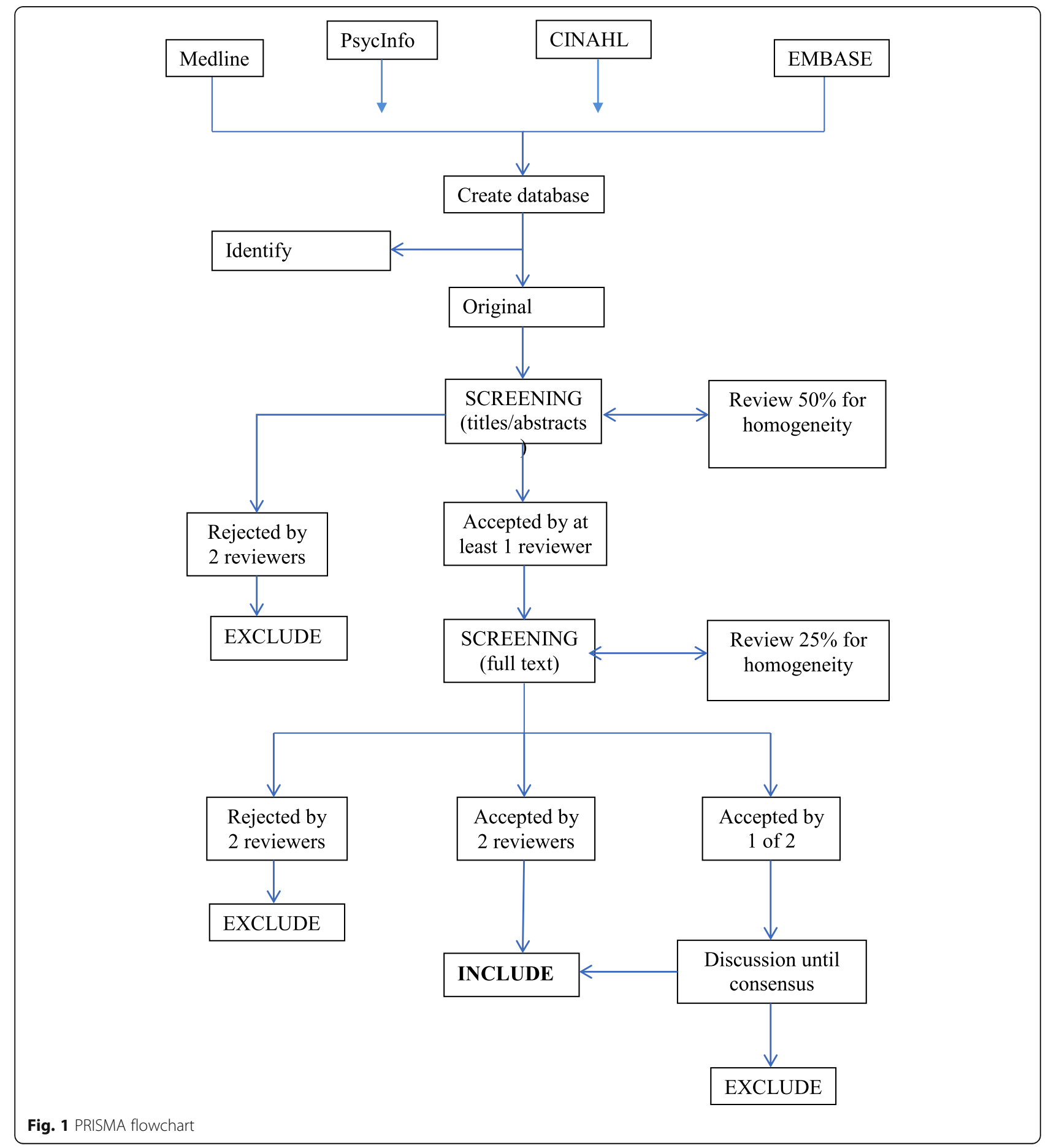


Phenomena of interest: medication safety/medicines management issues for visually impaired patients. On the basis of previous research, we anticipate that such issues may include being unable to open medication containers, being unable to differentiate various types of medication containers, being unable to differentiate various types of tablets/capsule dosage forms, forgetting to take medication on time and taking the wrong medication and polypharmacy (Zhi-Han, 2017: Cheraghi-Sohi et al, 2014.

Setting/context: Studies conducted in any setting. We will not restrict our search in specific geographical areas or date of publication.

We will exclude:

- Non-empirical studies

- Case studies reporting a new onset of visual impairment following medication use

- Articles in non-English languages

\section{Management of search outcomes and study eligibility screening}

The results of the searches of each database will be exported to COVIDENCE [1] and duplicates deleted.

Using PRISMA guidelines (Moher et al, 2009), screening will be completed in two stages (see Fig. 1). Initially, the titles and abstracts of the identified studies will be screened for eligibility (see the "Eligibility criteria" section). A proportion of titles and abstracts $(50 \%)$ will be screened by two researchers independently to assess reliability using the kappa statistic. Assuming reliability is confirmed, screening of the remaining titles and abstracts will be completed by one reviewer.

Next, the full texts of studies initially assessed as "relevant" for the review will be retrieved and checked against our inclusion/exclusion criteria. Full-text screening will be completed by two members of the research team independently, with disagreements resolved by discussion.

\section{Methodological quality of the studies}

As scoping reviews aim to provide a map of what evidence has been produced as opposed to seeking only the best available evidence to answer a particular question related to policy and practice, a formal assessment of methodological quality of the included studies of a scoping review will not be performed.

\section{Data synthesis}

A narrative synthesis will be conducted and the results will be organised according to the research aims. The first section of the results will present the research findings on the association between medication safety and visual impairment, the main types of patient safety issues encountered by people with visual impairment and the key contributory factors. The second section will focus on presenting the available evidence on the use of digital technologies for managing medication among people with visual impairment. In the third section, we will outline future research recommendations for designing and testing digital interventions to improve medication safety in people with visual impairment. We will take into consideration the present findings as well as the broader literature (from existing systematic reviews) on the use of digital technologies in improving medication safety.

\section{Discussion}

This review will summarise the literature relating to visual impairment and medication safety. Four electronic bibliographic databases will be searched, using combinations of two key blocks of search terms: visual impairment and medication safety. The findings from this review will provide an evidence base for further work in this area. It will increase understanding of the issues that visually impaired people face in relation to medication safety and ultimately improve quality of health care.

\section{Abbreviations \\ VI: Visual impairment; SG: Sally Giles; LR: Lisa Riste; RM: Rebecca Morris; SCS: Sudeh Cheraghi-Sohi; PL: Penny Lewis; AIS: Accessible Information} Standard

\section{Acknowledgements}

Not applicable

Authors' contributions

SG and MP designed the review and drafted the manuscript. All authors read and approved the final manuscript.

\section{Funding}

This research was funded by the National Institute for Health Research through the Greater Manchester Patient Safety Translational Research Centre (NIHR Greater Manchester PSTRC). The views expressed are those of the authors and not necessarily those of the NIHR or Department of Health and Social Care.

Availability of data and materials

Not applicable

\section{Declarations}

Ethics approval and consent to participate

Not applicable

Consent for publication

Not applicable

Competing interests

There are no competing interests.

Author details

${ }^{1}$ NIHR Greater Manchester Patient Safety Translational Research Centre, University of Manchester, Suite 11, 7th floor, Williamson Building, Oxford Road M13 9PL, Manchester, UK. ${ }^{2}$ Centre for Primary Care, University of Manchester, Oxford Road M13 9PL, Manchester, UK. ${ }^{3}$ Division of Pharmacy and Optometry, School of Health Sciences, Faculty of Biology, Medicine and Health, University of Manchester, Manchester Academic Health Sciences Centre (MAHSC), Manchester, UK. 
Received: 26 October 2020 Accepted: 25 August 2021

\section{Published online: 15 September 2021}

\section{References}

1. Pascolini D, Mariotti SP. Global estimates of visual impairment: 2010. British Journal of Ophthalmology. 2012;96(5):614-8. https://doi.org/10.1136/ bjophthalmol-2011-300539.

2. Pezzullo L, Streatfeild J, Simkiss P, Shickle D. The economic impact of sight loss and blindness in the UK adult population. BMC Health Serv Res. 2018; 18(1):63. https://doi.org/10.1186/s12913-018-2836-0.

3. Office for Disability Issues, 2011. Life Opportunities Survey 2009-2011. HM Government, Crown

4. Cupples M.E, Hart P.M, Johnston A et al. Improving healthcare access for people with visual impairment and blindness. BMJ 2012; 344 doi: 4 (Published 30 January 2012)

5. Lecko C. Patient safety and nutrition and hydration in the elderly. The Health Foundation; 2013.

6. Sharts-Hopko, Smeltzer S, Ott B et al. Healthcare experiences of women with visual impairment. Clinical Nurse Specialist: May-June 2010 - Volume 24 - Issue 3 - p 149-153

7. Zhi-Han L, Hui-Yin Y, Makmor-Bakry M. Medication-handling challenges among visually impaired population. Archives of Pharmacy Practice. 2017; 8(1):8-14.

8. Cheraghi-Sohi S, Jeffries M, Stevenson F, Ashcroft DM, Carr M, Oliver K, et al. The influence of personal communities on the self-management of medication taking: A wider exploration of medicine work. Chronic IIIn. 2015 Jun;11(2):77-92. https://doi.org/10.1177/1742395314537841 Epub 2014 Jun 11. PMID: 24920009.

9. NHS England. Making health and social care information accessible. July 2015. Available at: https:/www.england.nhs.uk/wp-content/uploads/2015/ 07/access-info-upd-july-15.pdf 0

10. Miller Smedema, S and McKenzie, A.R. (2010) The relationship among frequency and type of internet use, perceived social support, and sense of well-being in individuals with visual impairments, Disability and Rehabilitation, 32:4, 317-325, DOl: https://doi.org/10.3109/09638280903 095908

11. Meyer CH, Stanzel BV, Mogaddem S, Brohlburg D. [Healthcare "Apps" for smartphones: relief or toy for patients and the visual impaired?]. Der Ophthalmologe : Zeitschrift der Deutschen Ophthalmologischen Gesellschaft. 2012 Jan;109(1):21-29. DOl: https://doi.org/10.1007/s00347011-2426-6, Apps für Smartphones im Gesundheitsbereich.

12. Kim HN. Understanding of how older adults with low vision obtain, process, and understand health information and services. Informatics for Health and Social Care. 2017:44(1):70-8. https://doi.org/10.1080/17538157.2017.1363763.

13. World Health Organisation (WHO). Medication without harm. https://www. who.int/patientsafety/medication-safety/campaign/en/, accessed, May 2020

14. Giles, Sally J., Lewis, Penny J., Phipps, Denham L., Mann, Faith", Avery Anthony J. and Ashcroft, Darren M. PhD ${ }^{* \dagger}$ Capturing Patients' Perspectives on Medication Safety. Journal of Patient Safety: March 11, 2019

15. Maaskant JM, Vermeulen H, Apampa B, Fernando B, Ghaleb M A, Neubert A, Thayyil S, Soe A. Interventions for reducing medication errors in children in hospital. Cochrane Database of Systematic Reviews, $10^{\text {th }}$ March 2015

16. Kentab BY, Barry HE, Al-Aqeel Sinaa A, Hughes CM. A systematic review of pharmacists' interventions to support medicines optimisation in patients with visual impairment. International Journal of Clinical Pharmacy. 2019; 41(6):1400-7. https://doi.org/10.1007/s11096-019.

\section{Publisher's Note}

Springer Nature remains neutral with regard to jurisdictional claims in published maps and institutional affiliations.

Ready to submit your research? Choose BMC and benefit from:

- fast, convenient online submission

- thorough peer review by experienced researchers in your field

- rapid publication on acceptance

- support for research data, including large and complex data types

- gold Open Access which fosters wider collaboration and increased citations

- maximum visibility for your research: over $100 \mathrm{M}$ website views per year

At BMC, research is always in progress.

Learn more biomedcentral.com/submissions 